\section{Confocal laser endomicroscopy for the diagnosis of diversion colitis}

Confocal laser endomicroscopy (CLE) and virtual chromoendoscopy (VCE) are advanced endoscopic imaging techniques. $i$-Scan (Pentax, Japan) is a contrast-enhancing computed program [1], while CLE enables in vivo histological examination $[2,3]$.

Studies from our group described the diagnostic utility of CLE and VCE, such as for Crohn's disease [4-6]. However, data regarding the applicability of VCE and
CLE for the diagnosis of diversion colitis have not been provided so far.

Here, we describe the case of a 33-yearold woman who underwent an ileocecal resection and colorectal diversion 4 years previously because of a complicated ileocecal and rectal endometriosis with poor postoperative wound healing and the occurrence of a rectovaginal fistula. She reported diarrheic stools, which were still abundant (12-15 occurrences of diar- rhea/day) even after a therapeutic attempt with high-dose steroids and antibiotics.

High definition endoscopy (EPK-i, Pentax, Japan) showed a highly inflamed and friable mucosa with large ulcerations, loss of haustration, spontaneous bleeding, and mucus mixed with pus in the lumen ( $\bullet$ Fig.1a) of the diverted colorectum. Subsequent examination of the same area by CLE (Pentax EC-3870 CIFK, Japan) upon intravenous administration of fluorescein as a contrast agent, revealed a pronounced crypt rarefaction, hypervascularization with moderate leakage, and typical crypt abscesses ( $\mathbf{F i g} \mathbf{1} \mathbf{b}$ ).

Subsequent histopathological evaluation (hematoxylin and eosin stain) of conven-
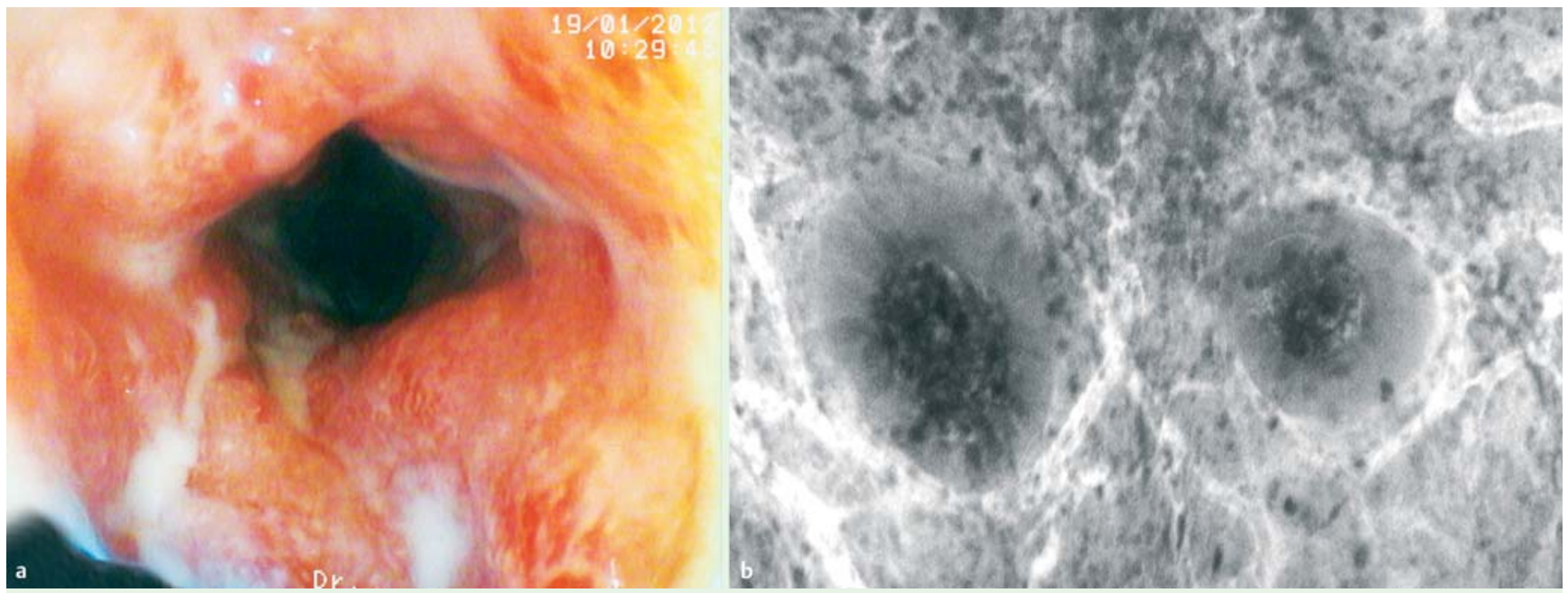

Fig. 1 a High definition white-light endoscopy reveals a highly inflamed and friable mucosa with large ulcerations, loss of haustration, and mucus mixed with pus, in the lumen of the sigmoid colon. $\mathbf{b}$ Confocal laser endomicroscopy of the same colonic area shows rarefied crypts with large lumens which are invaded by a dense polymorph infiltrate (crypt abscesses), as well as hypervascularization with mild leakage in the lamina propria.

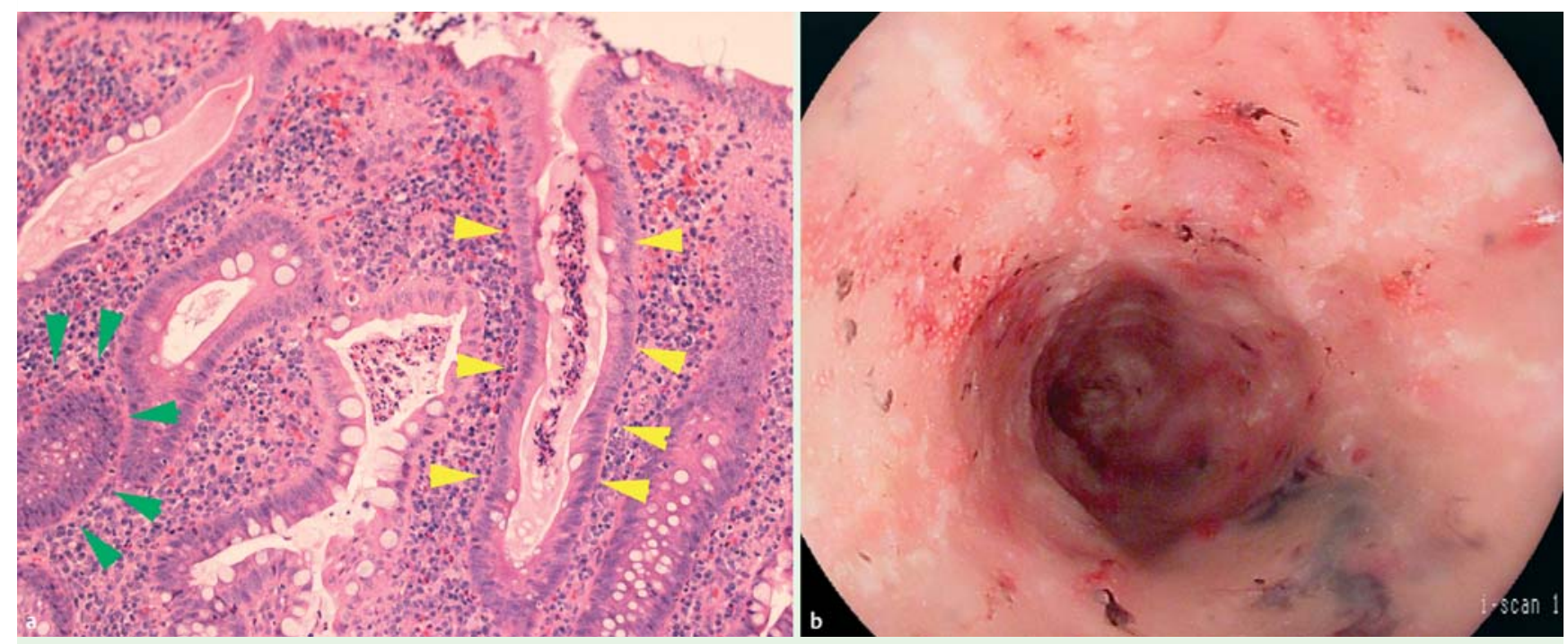

Fig. 2 a Conventional hematoxylin and eosin stain of a biopsy sample from the same area as in $\bullet$ Fig. 1 shows similar crypt abscess findings (cross-sectioned crypt marked by green arrowheads, and longitudinal sectioned crypt highlighted by yellow arrowheads) confirming the endomicroscopic diagnosis. $\mathbf{b}$ A high definition virtual chromoendoscopy image (i-Scan) of an improved colonic mucosa with deposits (but without ulcerations) in the same patient after 10 weeks of topical salicylate therapy. (The intense erythematous aspect is due also to the contrast enhancement of the i-Scan mode.) 
tional biopsies taken from the same location confirmed the endomicroscopic findings ( Fig. 2a). There was no evidence of cytomegalovirus with the specific stain. As a therapeutic consequence, the patient received topical therapy with salicylates. In a control colonoscopy with $i$-Scan, performed approximately 10 weeks later, we saw an endoscopic improvement of the colitis ( Fig. $\mathbf{2}$ b), a fact that confirmed our diagnosis and choice of specific therapy.

In conclusion, this article reports the first description and in vivo diagnosis of diversion colitis after surgery, by virtual chromoendoscopy and fluorescein-guided CLE, respectively.

Endoscopy_UCTN_Code_CCL_1AD_2AD

Competing interests: None

\section{G. Hundorfean, M. T. Chiriac, J. Siebler, M. F. Neurath, J. Mudter}

Medical Clinic I, University of Erlangen-Nuremberg, Erlangen, Germany

\section{Acknowledgment \\ $\nabla$}

We thank M. Vieth, Institute of Pathology, Klinikum Bayreuth, Bayreuth, Germany, for providing the histologic image ( $\bullet$ Fig. 2a) and for helpful discussions.

\section{References}

1 Kodashima S, Fujishiro M. Novel image-enhanced endoscopy with i-scan technology. World J Gastroenterol 2010; 16: 1043

2 Kiesslich R, Goetz M, Hoffman A, Galle PR. New imaging techniques and opportunities in endoscopy. Nat Rev Gastroenterol Hepatol 2011; 8: 547-553

3 Inoue H, Kudo SE, Shiokawa A. Technology insight: laser-scanning confocal microscopy and endocytoscopy for cellular observation of the gastrointestinal tract. Nat Clin Pract Gastroenterol Hepatol 2005; 2: 31-37
4 Hundorfean G, Agaimy A, Atreya R et al. Confocal laser endomicroscopy for characterization of Crohn's disease-associated duodenitis. Endoscopy 2012; 44: E80

5 Hundorfean G, Agaimy A, Hartmann A et al. In vivo diagnosis and characterization of gastric Crohn's disease using endomicroscopy and virtual chromoendoscopy. Endoscopy 2012 (in press)

6 Neumann H, Vieth M, Atreya R et al. Assessment of Crohn's disease activity by confocal laser endomicroscopy. Inflamm Bowel Dis 2012: DOI: $10.1002 /$ ibd.22907

\section{Bibliography}

DOI http://dx.doi.org/

10.1055/s-0032-1310019

Endoscopy 2012; 44: E358-E359

(c) Georg Thieme Verlag KG

Stuttgart · New York

ISSN 0013-726X

\section{Corresponding author}

\section{G. Hundorfean, MD}

Medical Clinic I

University of Erlangen-Nuremberg

Ulmenweg 18

91054 Erlangen

Germany

Fax: +49-9131-8535102

gheorghe.hundorfean@uk-erlangen.de 